\title{
Indirect flight muscles in Drosophila melanogaster as a tractable model to study muscle development and disease
}

\author{
SAROJ JAWKAR ${ }^{1}$ and UPENDRA NONGTHOMBA ${ }^{*}, 1$ \\ Department of Molecular Reproduction, Development and Genetics; Indian Institute of Science, Bangalore, India
}

\begin{abstract}
Myogenesis is a complex multifactorial process leading to the formation of the adult muscle. An amalgamation of autonomous processes including myoblast fusion and myofibrillogenesis, as well as non-autonomous processes, such as innervations from neurons and precise connections with attachment sites, are responsible for successful development and function of muscles. In this review, we describe the development of the indirect flight muscles (IFMs) in Drosophila melanogaster, and highlight the use of the IFMs as a model for studying muscle development and disease, based on recent studies on the development and function of IFMs.
\end{abstract}

KEY WORDS: Drosophila, indirect flight muscle, disease, muscle, myoblast

\section{Myogenesis, muscular dystrophies and models to study muscle development}

Vertebrate myogenesis takes place in two major stages: developmental (prenatal) myogenesis and adult (postnatal) myogenesis (reviewed in Taylor, 2006). The first step in developmental myogenesis is primary myogenesis, which aims to establish the basic pattern of the musculature. This is followed by secondary myogenesis, marked by a period of growth and maturation of the muscle. Adult myogenesis occurs postnatally, and comprises of growth and repair of damaged muscle tissue in the adult organism. Primary and secondary myogenesis are essential for development of the musculature, while adult myogenesis is required for maintenance and function of the adult musculature.

In vitro model systems like primary cell cultures established from human patients, and mouse $\mathrm{C} 2 \mathrm{C} 12$ myoblasts, and in vivo model systems like the mouse, zebrafish and chick embryo, have contributed immensely to the understanding of developmental and adult myogenesis. However, the use of in vitro model systems to understand myogenesis is limited, as myogenesis is a combinatorial process involving inputs from the developing muscle, neurons, and the target attachment sites. Despite providing a wealth of information with regard to developmental myogenesis, use of the available in vivo model systems (mice and zebrafish) is limited by factors such as the long time period of muscle development, complexity of the genome of the organism, and limitations in the genetic manipulations that can be performed. In contrast to these systems, the indirect flight muscles (IFMs) of Drosophila melanogaster offer several advantages as a model system for studying muscle development and function, as compared to both in vitro and other in vivo models. The smaller size of the its genome, and the shorter developmental time have made the fruit fly a popular model for studying developmental and cell biological processes. In this review, we describe the development of the indirect flight muscles (IFMs) of Drosophila melanogaster, and spotlight them as an attractive in vivo model system to study developmental and adult myogenesis, as well as muscle disease.

\section{Architecture and development of the indirect flight muscles}

The fly, being a holometabolous insect, is characterized by two distinct mobile stages in its development, namely the larval and the adult stages. These stages have a dedicated musculature, suitably tailored to meet the demands of that particular stage.

The IFMs are the major occupants of the thorax of the adult fly, and are responsible for powering the wing stroke during flight (Josephson et al., 2000; Agianian et al., 2004). These muscles consist of two opposing sets of muscles, namely the dorso-longitudinal muscles (DLMs) (Fig. 1, oriented anterior to posterior; highlighted in orange), and the dorso-ventral muscles (DVMs) (Fig. 1, oriented in a dorsal-to-ventral manner; highlighted in purple). The DVM bundles are subdivided into DVM I (3 fibers), DVM II (2 fibers) and DVM III (2 fibers). The ultrastructure of the DLMs and the DVMs is identical (Fernandes and Keshishian, 1996; Fernandes et al.,

Abbreviations used in this paper: IFM, indirect flight muscle. *Address correspondence to: Upendra Nongthomba. Department of Molecular Reproduction, Development and Genetics; Indian Institute of Science, Bangalore,
560012, India. E-mail: upendra@iisc.ac.in - (D) https://orcid.org/0000-0002-0616-5995 


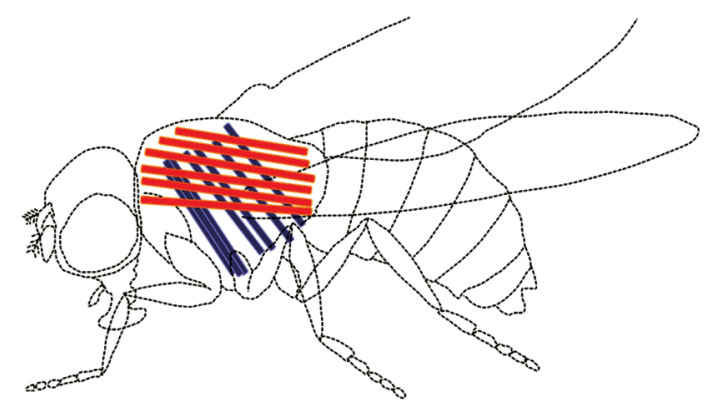

Fig. 1. Schematic highlighting the indirect flight muscles (IFMs) of Drosophila melanogaster. They comprise of the DLMs (orange) and DVMs (purple), which are arranged across the anterior-posterior axis and the dorso-ventral axis of the adult fly, respectively.

\section{1; Vigoreaux, 2006).}

The adult musculature largely develops after histolysis of the larval musculature, during the interim pupal stage. However, adult myogenesis is initiated in the embryonic stages of fly development, when few asymmetric divisions of myogenic progenitors (derived from the mesoderm) gives rise to a founder cell (required in development of the embryonic musculature), and a twist-expressing adult muscle precursor (AMP). These AMPs continue to remain dormant throughout the subsequent stages of embryonic development. The AMPs destined for development of the IFMs are housed in the notum region of the wing imaginal disc, where they proliferate during the larval stage of IFM development. A few cells from the pool of AMPs are set aside as satellite cells, with an aim to repair damaged muscle in case of injury or disease (Fernandes et al., 1991; Chaturvedi et al., 2017) (Fig. 2).

The hallmarks of the pupal stage of IFM myogenesis are myoblast fusion, innervation and formation of attachments with the tendon cells, followed by myofibrillogeneis. Myoblast fusion occurs in the first quarter of metamorphosis. The DLMs and DVMs develop differentially during pupation, wherein DVMs form solely by de novo fusion of myoblasts, similar to vertebrate muscles. DLMs, on the contrary, are formed by fusion of myoblasts with pre-existing templates. These templates, also called as the larval oblique muscles (LOMs), are derived from the dorsal oblique muscles (DO1) of the

\section{Embryonic stage}

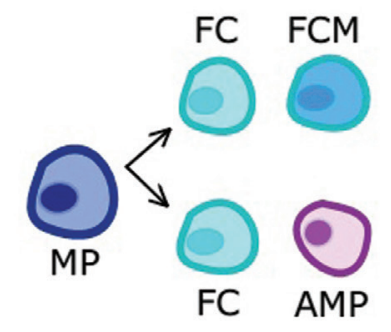

\section{Larval stage}

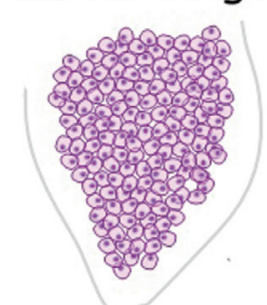

Multiplcation of AMPs on the wing disc. Satellite cells set aside

Fig. 2. Schematic depiction of specification and proliferation of the adult muscle precursors (AMPs) during the embryonic and larval stages respectively (MP, muscle precursor; FC, founder cell; FCM, fusion competent myoblasts).
Notum of wing disc

(n)

larva. After the initiation of metamorphosis, vestigial-expressing AMPs detach from the everting wing disc and migrate towards the templates. Formation of DLMs is primarily guided by these LOMs, which consist of Dumbfounded (Duf)-expressing cells. Myoblasts migrate towards the three LOMs, and the developing fibers split to give rise to 6 primitive fascicles of the IFM. In the case of DVM development, Duf-expressing myoblasts fuse with nearby myoblasts to give rise to a primary fiber, which in turn acts as a seed for further fusion events. Myoblast fusion continues for the first quarter of metamorphosis, while epidermal contact and innervation is established as the fiber develops, and is discussed later (Farrell et al., 1996; Fernandes and Keshishian, 1996; Fernandes et al., 1991; Guruharsha et al., 2009; Rivlin et al., 2000) (Fig. 3).

As myoblast fusion comes to an end, the developing fiber segues into myofibrillogenesis, during which the nascent myotube matures into a myofiber. Each myofiber consists of multiple myofibrils which span the entire length of the fiber. Each myofibril in turn, consists of repeating contractile units called sarcomeres formed by arrays of actin and myosin filaments. Myofibrillogenesis of the IFMs is initiated by contraction of the muscle fiber and spans the remaining duration of metamorphosis. The mechanical tension generated by this contraction is instrumental in the initiation of myofibrillogenesis. Immature myofibrils assemble simultaneously, and short sarcomeres are added to each myofibril. This is followed by maturation of the growing sarcomere over the remainder of metamorphosis, to attain its final dimensions, density of mitochondria (Rai et al., 2014) and isoforms of structural proteins tailored to the functional requirements of the IFMs (Chechenova et al., 2013; Katzemich et al., 2012; Nongthomba et al., 2004; 2007; Orfanos et al., 2015; Reedy and Beall, 1993; Reedy et al., 2000; Shwartz et al., 2016; Spletter et al., 2018). Myofibrillogenesis involves formation of stress fibre-like structures (SFLS) (Reedy and Beall, 1993), orthologous to the vertebrate I-Z-I bodies (Ehler et al., 1999; Ojima et al., 1999), which are precursors to the assembly of sarcomeres. Major structural proteins, like myosin, actin, tropomyosin, troponin, and $\alpha$-actinin, etc., that are involved in the assembly of organized sarcomeres are conserved in vertebrates and Drosophila, and dispense similar functions (Bernstein et al., 1993; Vigoreaux, 2001). Transcripts for most of these structural proteins are expressed very early during IFM development. However, actual assembly of these proteins for formation of the sarcomere takes place only after differentiation (Nongthomba et al., 2004). Flightin, a thick filamentassociated protein that interacts with the myosin rod, is required for the establishment of normal thick filament length during late pupal development, and the maintenance of the stability of the thick filaments in adults (Reedy et al., 2000; Ayer and Vigoreaux 2003). Similarly, the Tropomodulin (Tmod1) gene sanpodo, 


\section{Neurons guiding indirect flight muscle development}

Muscle function and physiology is contingent on pertinent innervation of the muscle by motor neurons, in addition to the development of the musculature itself. Successful innervation includes development of synapses, comprising of the terminals of a motor neuron axon and a muscle fiber. Since a dialogue between the nerve and the muscle is essential for the development, and subsequent maintenance, of the vertebrate neuromuscular junction (NMJ), the muscle and its associated neuronal branching develop simultaneously.

Delving into development of IFM innervation, the neuromuscular system in the adult fly develops mainly by re-specification of larval motor neurons during metamorphosis (Fernandes and Keshishian, 1998). The timeline of development of the innervation of the IFMs has been described previously (Fernandes and Vijayraghavan, 1993; Hebbar and Fernandes, 2004). Briefly, at the onset of metamorphosis, retraction of the larval NMJs is observed, followed by

A

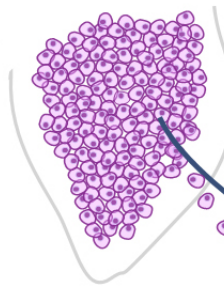

-12h APF: Larval dorsal oblique muscles (LOMs) escape histolysis formation of the DLMs. Myoblasts on the wing disc migratetowards and fuse with the LOMs and serve as a template for the

B

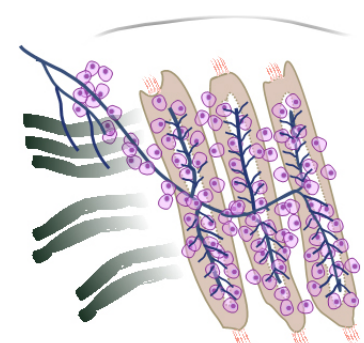

14-18h APF: The growing DLMS split to form six DLMs. DVMs can be seen. Filopdial extensions emanate from the ends of the templates. Extensive outgrowths of the primary branches extending over the splitting templates are observed.

\section{B'}

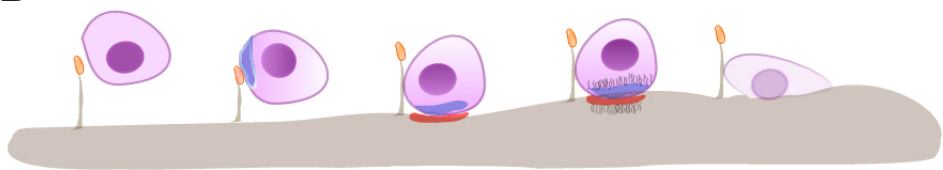

Myoblast fusion: Fusion competent myoblasts down-regulate expression of Notch, and concomitantly express fusion-related genes such as SnS. Contact with filopodia on the myotube leads to accumulation of the SnS near the site of contact. Once the myoblast is in close contact with the developing fascicle, the clustered SnS molecules on the myoblast recruit Duf on the myotube. Actin accumulates at the fusogenic synapse leading to fusion of the myoblast into the developing myotube.

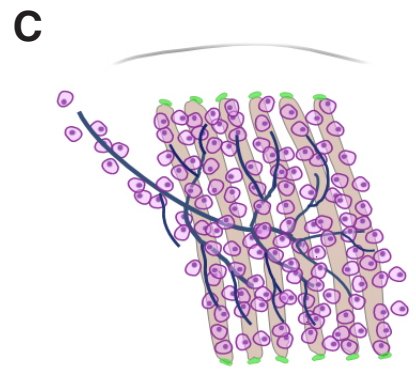

18-24h APF: Myoblast fusion continues till 24h APF. DLMs and DVMs are innervated by multiple second order branches. Integrins start to accumulate on the ends of the developing fascicles

Fig. 3. Development of the indirect flight muscles, their innervation and attachments with the epidermis during the early stages of pupation. adult specific motor neuron outgrowth over the larval scaffolds to innervate the newly developing adult musculature. This is followed by the development of transverse second-order branches. IFM development and neuronal innervation occur simultaneously, wherein higher-order synapses appear as the nascent fiber develops, thereby allowing for nerve-muscle interactions to shape the developing neuromuscular pattern. By 24h APF, the DLMs and DVMs are innervated by multiple second-order branches and their higher-order arbors (Hebbar and Fernandes, 2004). From 24-38h APF, defasciculation of the primary neuronal branches ensues in the DLMs, accompanied by pruning of the second-order branches and initiation of the formation of boutons. These boutons continue to develop in number and size through the course of metamorphosis, to finally give rise to the neuromusculature of the adult fly. Innervation is necessary for the formation of the IFMs, as laser ablation of the mesothoracic nerve innervating the IFMs led to a patterning defect, which included delayed growth of the DLMs and no growth of the DVMs (Fernandes and Keshishian, 1998). This effect was primarily due to decreased myoblast proliferation. However, migration and localization of the myoblasts remained unaffected. Neuronal input was also shown to be required for the expression of the founder cell specific marker, Duf, in the myoblasts forming the DVMs, while its expression in the LOMs forming the DLMs remained unchanged (Fernandes and Keshishian, 2005). Laser ablation of the DLMs led to a nerve-dependant formation of muscle fibers, similar to the de novo method of DVM development (Fernandes and Keshishian, 1998). Evidence of a dialogue between the components of the neuromusculature came from studies where the defective innervation pattern in the DLMs of the Fasciclin 2 (Fas2) mutant was rescued by its ectopic neuronal and muscle expression (Hebbar and Fernandes, 2005).

Thus, the simultaneous development of the IFMs and its innervations allows researchers to dissect out mechanisms by which synaptic partners may influence development and/or function of each other. Due to their inherent mode of development, the DLMs and DVMs provide a dual system to study development of the neuromusculature under template-dependant and template-independent conditions respectively. This is unlike in vitro model systems, where muscle fibers develop independent of the neuronal input. Combining these characteristics with the ease to genetically modulate synaptic components, and its susceptibility to laser ablation, makes the IFM a tractable model for studying NMJ development.

\section{Impact of epidermal cues on indirect flight muscle development}

The myotendinous junction (MTJ) is found at the cusp of the muscle and epithelial tendon cell, where contractile forces are transmitted from the muscle onto the tendon cells. The three distinct stages of MTJ development are (1) migration of the growing myotube towards their specific tendon targets, followed by (2) attachment initiation, where the myotube and tendon cells interdigitate and initiate attachment, finally leading to (3) attachment maturation (Weitkunat et al., 2014). Similar to the flight muscles, cells 
destined to form attachment sites are prefigured on the notum region of the wing imaginal discs of late third instar larva. These cells are defined by the expression of stripe, and are vital for IFM development (Ghazi et al., 2000).

As the muscle is a contractile unit, it requires attachment to tendon cells on either side of the sarcolemma. Hence, precise development of the IFMs hinges on the development and subsequent attachment with tendon cells. The first evidence of a role of the epidermis on IFM development came from studies on the dumpymutants. These mutants showed defective attachments for all muscles of the thorax, displaced muscles with decreased muscle mass, which eventually led to breakdown of muscles (Metcalfe, 1970).

Subsequently, a number of genes have been identified which regulate gene expression and development of the IFMs, even though they are expressed in the attachment sites. The most prominent is stripe, which marks the anterior and posterior attachment sites of the IFMs. These stripe-expressing epidermal cells contact the developing muscles, leading to the formation of the MTJ (Fernandes et al., 1996). The DLMs in pannier mutants attach dorsoventrally (like the DVM-III) instead of anterio-posterioraly (Ghazi et al., 2003). Stripe expression is pivotal for maintaining the expression of Duf in the LOMs of the DLMs (Dutta et al., 2004). Apterous, a known regulator of stripe expression, also regulates IFM patterning. Apterous is highly expressed at the posterior attachment sites of the DLS, and apterous mutants have thinner posterior attachments accompanied with incomplete splitting of the templates, leading to a patterning defect (Ghazi et al., 2000).

The IFMs in mutants of the Broad-complex transcription factors, like BRC-Z1, show defective attachment to the epidermis. Additional defects observed were: incomplete splitting of the DLMs, reduced number of DVMs, and missing DLM fibers in some cases. Genetic mosaic experiments corroborated the role for the dorsal epidermis in guiding precise attachment of muscles on to target sites on the epidermis (Sandstrom and Restifo, 1999; Sandstrom et al., 1997). IFMs in semi-lethal flapwing mutants develop normally up to $24 \mathrm{~h}$ APF, but consequently break away from their posterior attachment sites and collect at the anterior segment boundaries as ball-like structures. The protein phosphatase, Pp1B9C, encoded by the flw gene, is required in both muscles and epidermal cells for development of attachment sites (Raghavan et al., 2000). Additionally, studies have shown that muscles, in turn, regulate planar cell polarity on the notum epithelium (Glavic et al., 2011; Metcalfe, 1970; Vega-Macaya et al., 2016). A recent study has introduced a new player, dRok (a Rho Kinase), into the line-up of tendon cell-specific molecules regulating IFM development. Flies lacking $d R o k$ display faulty targeting of tendon-cell processes to the IFMs, leading to abnormal muscle myogenesis and detachment (Vega-Macaya et al., 2016).

In an elegant study, Weitkunat and co-workers have shown that mechanical tension generated at the MTJ during MTJ maturation, is crucial in the initiation of myofibrillogenesis in the developing IFMs. They also identified Kontiki, as a key epidermal regulator of IFM development (Weitkunat et al., 2014).

\section{Indirect flight muscles as the model system to study muscular disorders and diseases:}

The adult musculature has had a low profile, but now it is apparent that it can serve as an excellent model to get a holistic view of muscle development, structure, function and disease. The time-course of the development of the IFMs offers advantages in dissecting individual processes involved in muscle development, in isolation, and thus, follow the aetiology of disease progression.

The IFMs provide a unique model system with which many molecular, developmental, structural and physiological questions pertaining to muscular disorders can be addressed. IFMs are dispensable to flies (they can survive without the IFMs in normal laboratory conditions), and any defect in development and assembly of these muscles, or stoichiometric imbalances leads to a defect in flight (easily assayed) allowing for functional analysis of the mutants, allowing functional annotation of any human mutation. They are relatively large, which permits biochemical and physiological approaches to assess muscle function (Swank et al., 2004; Dickinson et al., 2005). Many muscle structural proteins express IFM-specific isoforms, making it an effective genetic model with which to study the effect of absence of these isoforms on flight muscle function (Beall et al., 1989; Vigoreaux, 2001; Nongthomba et al., 2004) without affecting the viability of the fly.

Most importantly, IFMs share a close structural resemblance to the vertebrate skeletal muscles (Crossley 1978; Reedy and Beall, 1993; Taylor, 2006) and many of the human muscle disease-causing proteins have orthologs in the fly. There is an abundance of studies wherein mechanisms of human disease progression due to mutations in genes encoding structural proteins have been deciphered using the IFMs as a model system (Haigh et al., 2010; Cammarato et al., 2011, Wang et al., 2012, Salvi et al., 2012, Sevdali et al., 2013; Suggs et al., 2017 Viswanathan et al., 2017). The structural and physiological changes seen in these IFM mutants emulate their human counterparts. A recent study from our laboratory has demonstrated the use of IFMs to study a global transcriptional response in the absence of key muscle structural proteins. We identified that the genes whose expression is mis-regulated in absence of major structural proteins, reflect the genetic signatures found in case of major disease conditions in humans like Muscular Dystrophy (Madan et al., 2017). Unpublished data from our lab has also shown the use of IFMs to study $\mathrm{Ca}^{2+}$ oscillations in channelopathy mutants of Drosophila melanogaster (Jhonsa and Nongthomba, unpublished data). Different facets of disease progression in myopathies have also been studied in the IFMs (Shcherbata et al., 2007, de Haro et al., 2006, Ueyama et al., 2010, Allikian et al., 2007., Chartier et al., 2006, Kucherenko et al., 2008), thus, highlighting its use as a model system to study muscle diseases/disorders and their aetiology/mechanisms.

Additionally, IFM can also serve as a valuable system for dissecting functions of the novel genes and their regulatory networks, identified through large-scale gene expression profiling during differentiation of the human skeletal myoblast cell lines (Sterrenburg et al., 2004) and C2C12 myoblasts (Tomczak et al., 2003; Blais et al., 2005). Thus, the wide repertoire of experimental tools available, and the characteristics of the tissue, facilitate the synthesis of a comprehensive description of how muscle develops and functions in case of a disease/disorder.

\section{Moonlighting functions of indirect flight muscles and role in homeostasis}

Muscles, whilst most known for their functions in movement, digestion, contraction of the heart, and respiration, are now being highlighted for their functions in maintaining homeostasis, directly or 
indirectly, via communication with other organ systems. This action is performed by secreted cytokines and growth factors, collectively called myokines, which act in autocrine, paracrine or endocrine manners, to regulate biological processes at their target tissues. Evidence for regulation of biological processes by myokines in non-muscle cells came through multiple studies (Bouzakri et al., 2011; Quinn et al., 2008; Seldin et al., 2012; Zeng et al., 2010). These studies have shown the role of muscle-derived factors in regulating systemic lipid homeostasis, pancreatic B-cell function, muscle injury and regeneration, and fat deposition.

Similarly, in Drosophila, muscle-derived factors like Myoglianin, dawdle, and ImpL2 have been highlighted for their role in regulating physiology and lifespan, and IFMs, being the largest muscles, could be a source of factors like Myoglianin and ImpL2. At the inter-organ level, muscle-derived myoglianin was shown to reduce nucleolar size in fat bodies, decrease rRNA levels, increase lifespan, and enhance healthy aging at the organism level (Demontis et al., 2014). Surprisingly, muscle mitochondria have also been shown to be instrumental in inter-organ communication. Ectopic expression of ImpL2 in flight muscles, or limited perturbation of mitochondrial function in adult muscles, leads to $\mathrm{ImpL} 2$ secretion, which non-autonomously inhibits insulin secretion and extends lifespan (Owusu-Ansah et al., 2013). This extension of lifespan is likely through the removal of protein aggregates by the actions of FOXO, and its target 4EBP, which activates autophagy. FOXO expression in the muscle led to both autonomous and non-autonomous increase in 4E-BP activity, and consequent clearance of age-related protein aggregates, thus, leading to healthy aging (Demontis and Perrimon, 2010). Extension of lifespan was also observed by increasing autophagy, and by inhibiting activin signalling in the muscle (Bai et al., 2013). In a recent study, Zhao and Karpac put IFMs at the core of energy homeostasis in Drosophila, wherein they demonstrate that FOXO-mediated expression of upd in IFMs activates Adipokinetic Hormone (AKH) secretion, from specific neuroendocrine cells, which regulates systemic lipid synthesis, and circulating lipid levels (Zhao and Karpac, 2017). In addition to their role in inter-organ communication and aging, IFMs moonlight as regulators of immune response to infections. Specifically, IFMs produce anti-microbial peptides upon infection, and this immune response is crucial for survival upon bacterial infection (Chatterjee et al., 2016). Taken together, IFMs can be used a model system to study muscle-mediated regulation of function of distant organs.

\section{Concluding remarks}

In conclusion, in IFMs we have a system where we can combine powerful, incisive genetics, with molecular and cellular analyses of muscle development, and structure/function studies to establish a link between genotype and phenotype, which can provide valuable insight into understanding human muscle development, and disease progression.

\section{Acknowledgements}

We thank Amartya Mukherjee for help with editing, and Vishakha Nesari and Aditi Mishra for critical assessment of the manuscript. UN is supported by financial assistance from Indian Institute of Science (IISc), the Department of Science and Technology (DST) (DST FIST, 2008-2013 Ref. No. SR/FST/LSII-018/2007), the University Grant Commission (UGC-SAP to MRDG: Ref. No. F.3-47/2009 (SAP-II) and the Department of Biotechnology (DBT), Govt. of India, (DBT-IISC Partnership Program for Advanced
Research in Biological Sciences \& Bioengineering Sanction Order No: DBT/BF/PRIns/2011-12/ISc/28.9.2012).

\section{References}

AGIANIAN, B., KRZIC, U., QIU F., LINKE, W. A., LEONARD K. et al., (2004). A troponin switch that regulates muscle contraction by stretch instead of calcium. EMBO J. 23: 772-779.

ALLIKIAN, M. J., BHABHA, G., DOSPOY, P., HEYDEMANN, A., et al., (2007). Reduced life span with heart and muscle dysfunction in Drosophila sarcoglycan mutants. Hum Mol Genet. 16: 2933-2943.

AYER, G. and VIGOREAUX. J. O. (2003). Flightin is a myosin rod binding protein. Cell. Biochem. Biophys. 38: 41-54.

BAI, H., KANG, P., HERNANDEZ, A. M. and TATAR, M. (2013). Activin Signaling Targeted by Insulin/dFOXO Regulates Aging and Muscle Proteostasis in Drosophila. PLoS Genet. 9: e1003941.

BEALL, C. J., SEPANSKI, M. A. and FYRBERG, E. A. (1989). Genetic dissection of Drosophila myofibril formation: effects of actin and myosin heavy chain null alleles. Genes Dev. 3: 131-140.

BERNSTEIN, S. I., O'DONNELL, P. T. and CRIPPS, R. M. (1993). Molecular genetic analysis of muscle development, structure, and function in Drosophila. Int. Rev. Cytol. 143: 63-152.

BLAIS, A., TSIKITIS, M., ACOSTA-ALVEAR, D., SHARAN, R., KLUGER, Y. and DYNLACHT, B. D. (2005). An initial blueprint for myogenic differentiation. Genes \& Dev. 19: 553-569.

BOUKHATMI, H. and BRAY, S. (2018). A population of adult satellite-like cells in Drosophila is maintained through a switch in RNA-isoforms. Elife 7: e35954.

BOUZAKRI, K., PLOMGAARD, P., BERNEY, T., DONATH, M. Y., PEDERSEN, B. K. and HALBAN, P. A. (2011). Bimodal effect on pancreatic $\beta$-cells of secretory products from normal or insulin-resistant human skeletal muscle. Diabetes 60: 1111-1121.

CAMMARATO, A., AHRENS, C. H., ALAYARI, N. N., QELI, E. et al., (2011). A mighty small heart: the cardiac proteome of adult Drosophila melanogaster. PLoS One. 6: e18497.

CHATTERJEE, A., ROY, D., PATNAIK, E. and NONGTHOMBA, U. (2016). Muscles provide protection during microbial infection by activating innate immune response pathways in Drosophila and zebrafish. Dis. Model. Mech. 9: 697-705.

CHARTIER, A., BENOIT, B., SIMONELIG, M. A. (2006). Drosophila model of oculopharyngeal muscular dystrophy reveals intrinsic toxicity of PABPN1. EMBO J. 25: 2253-2262.

CHATURVEDI, D., REICHERT, H. and GUNAGE, R. D. (2017). Identification and functional characterization of muscle satellite cells in Drosophila. Elife 6: e30107.

CHECHENOVA, M. B., BRYANTSEV, A. L. and CRIPPS, R. M. (2013). The Drosophila $Z$-disc protein $Z(210)$ is an adult muscle isoform of Zasp52, which is required for normal myofibril organization in indirect flight muscles. J. Biol. Chem. 288: 3718-3726.

CROSSLEY, A. C. (1978). The morphology and development of the Drosophila muscular system. In Genetics and Biology of Drosophila, Vol 2b (ed. M Ashburner and T.R.F. Wright) 499-560. New York Academic Press.

DE HARO, M., AL-RAMAHI, I., DE GOUYON, B., UKANI, L. et al., (2006). MBNL1 and CUGBP1 modify expanded CUG-induced toxicity in a Drosophila model of myotonic dystrophy type 1. Hum Mol Genet. 15: 2138-2145.

DEMONTIS, F. and PERRIMON, N. (2010). FOXO/4E-BP signaling in Drosophila muscles regulates organism-wide proteostasis during aging. Cell 143: 813-825.

DEMONTIS, F., PATEL, V. K., SWINDELL, W. R. and PERRIMON, N. (2014). Intertissue control of the nucleolus via a myokine-dependent longevity pathway. Cell Rep. 7: 1481-1494.

DICKINSON, M. H., FARMAN, G., FRYE, M., BEKYAROVA, T., GORE, D., MAUGHAN D. and IRVING T. (2005). Molecular dynamics of cyclically contracting insect flight muscle in vivo. Nature 433: 330-333.

DUTTA, D., ANANT, S., RUIZ-GOMEZ, M., BATE. M. and VIJAYRAGHAVAN, K. (2004). Founder myoblasts and fibre number during adult myogenesis in Drosophila. Development 131: 3761-3772.

EHLER, E., ROTHEN, B. M., HÄMMERLE, S. P., KOMIYAMA, M. and PERRIARD, J. C. (1999). Myofibrillogenesis in the developing chicken heart: assembly of Z-disk, M-line and the thick filaments. J. Cell. Sci. 112: 1529-1539. 
FARRELL, E. R., FERNANDES, J. and KESHISHIAN, H. (1996). Muscle Organizers in Drosophila: The Role of Persistent Larval Fibers in Adult Flight Muscle Development. Dev. Biol. 176: 220-229.

FERNANDES, J. J. and KESHISHIAN, H. (1996). Patterning the dorsal longitudinal flight muscles (DLM) of Drosophila: insights from the ablation of larval scaffolds. Development 122: 3755-3763.

FERNANDES, J. J. and KESHISHIAN, H. (1998). Nerve-muscle interactions during flight muscle development in Drosophila. Development 125: 1769-1779.

FERNANDES, J. J. and KESHISHIAN, H. (2005). Motoneurons regulate myoblast proliferation and patterning in Drosophila. Dev Biol. 277: 493-505.

FERNANDES, J. and VIJAYRAGHAVAN, K. (1993). The development of indirect flight muscle innervation in Drosophila melanogaster. Mol. Biol. 227: 215-227.

FERNANDES, J., BATE, M. and VIJAYRAGHAVAN, K. (1991). Development of the indirect flight muscles of Drosophila. Development 113: 67-77.

FERNANDES, J. J., CELNIKER, S. E. and VIJAYRAGHAVAN, K. (1996). Development of the indirect flight muscle attachment sites in Drosophila: role of the PS integrins and the stripe gene. Dev. Biol. 176: 166-184.

FIRDAUS, H., MOHAN, J., NAZ, S., ARATHI, P., RAMESH, S. R., and NONGTHOMBA, U. (2015). A cis-regulatory mutation in troponin-I of Drosophila reveals the importance of proper stoichiometry of structural proteins during muscle assembly. Genetics 200: 149-165.

GHAZI, A., ANANT, S. and VIJAYRAGHAVAN, K. (2000). Apterous mediates development of direct flight muscles autonomously and indirect flight muscles through epidermal cues. Development 127: 5309-5318.

GHAZI, A., PAUL, L. and VIJAYRAGHAVAN, K. (2003). Prepattern genes and signaling molecules regulate stripe expression to specify Drosophila flight muscle attachment sites. Mech. Dev. 120: 519-528.

GLAVIC, A., MLODZIK, M. and OLGUI, P. (2011). Report Intertissue Mechanical Stress Affects Frizzled-Mediated Planar Cell Polarity in the Drosophila Notum Epidermis. Curr Biol. 21: 236-242.

GURUHARSHA, K. G., RUIZ-GOMEZ, M., RANGANATH, H. A., SIDDHARTHAN, R. (2009). The complex spatio-temporal regulation of the Drosophila myoblast attractant gene duf/kirre. PLoS One 4: e6960.

HAIGH, S. E., SALVI, S. S., SEVDALI, M., STARK, M. et al., (2010). Drosophila indirect flight muscle specific Act88F actin mutants as a model system for studying congenital myopathies of the human ACTA1 skeletal muscle actin gene. Neuromuscul. Disord. 20: 363-374.

HAKEDA, S., ENDO, S. and SAIGO, K. (2000). Requirements of Kettin, a giant muscle protein highly conserved in overall structure in evolution, for normal muscle function, viability, and flight activity of Drosophila. J. Cell Biol. 148: 101-114.

HEBBAR, S. and FERNANDES J. J. (2004). Pruning of motor neuron branches establishes the DLM innervation pattern in Drosophila. J. Neurobiol. 60: 499-516.

HEBBAR, S. and FERNANDES, J. J. (2005). A role for Fas II in the stabilization of motor neuron branches during pruning in Drosophila. Dev Biol. 285: 185-199.

JOSEPHSON, R. K., MALAMUD, J. G. and STOKES, D. R. (2000). Asynchronous muscle: a primer. J. Exp. Biol. 203: 2713-2722.

KATZEMICH, A., KREISKO, N., ALEXANDROVICH, A., ELLIOTT, C., et al., (2012). The function of the $\mathrm{M}$-line protein obscurin in controlling the symmetry of the sarcomere in the flight muscle of Drosophila. J Cell Sci. 125: 3367-3379.

KUCHERENKO, M. M., PANTOJA, M., YATSENKO, A. S., SHCHERBATA, H. R. et al., (2008). Genetic modifier screens reveal new components that interact with the Drosophila dystroglycan-dystrophin complex. PLoS One 3: e2418.

MARDAHL-DUMESNIL, M. and FOWLER, V. M. (2001). Thin filaments elongate from their pointed ends during myofibril assembly in Drosophila indirect flight muscle. J. Cell. Biol. 155: 1043-1053.

METCALFE, J.A. (1970). Developmental Genetics of Thoracic abnormalities of Dumpy mutants of Drosophila melanogaster. Genetics 65: 627-654.

Nongthomba, U., Clark, S., Cummins, M. C., Ansari, M., Stark M. et al., 2004 Troponin $\mathrm{I}$ is required for myofibrillogenesis and sarcomere formation in Drosophila flight muscle. J. Cell Sci. 117: 1795-1805.

NONGTHOMBA, U., ANSARI, M., THIMMAIYA, D., STARK, M. and SPARROW, J. C. (2007). Aberrant splicing of an alternative exon in the Drosophila troponin-T gene affects flight muscle development. Genetics 177: 295-306.

OJIMA, K., LIN, Z. X., ZHANG, Z. Q., HIJIKATA, T., HOLTZER, S., LABEIT, S.,
SWEENEY, H. L.AND HOLTZER, H. J. (1999). Initiation and maturation of I-Z-I bodies in the growth tips of transfected myotubes. J. Cell. Sci. 112: 4101-4112.

ORFANOS, Z., LEONARD, K., ELLIOTT, C., KATZEMICH, A., BULLARD, B. and SPARROW, J. (2015). Sallimus and the Dynamics of Sarcomere Assembly in Drosophila Flight Muscles. J. Mol. Biol. 427: 2151-2158.

OWUSU-ANSAH, E., SONG, W. and PERRIMON, N. (2013). Muscle Mitohormesis Promotes Longevity via Systemic Repression of Insulin Signaling. Cell 155: 699-712.

QUINN, L. S., ANDERSON, B. G., STRAIT-BODEY, L., STROUD, A. M. and ARGILES, J. M. (2008). Oversecretion of interleukin-15 from skeletal muscle reduces adiposity. AJP Endocrinol. Metab. 296: E191-E202.

RAGHAVAN, S., WILLIAMS, I., ASLAM, H., THOMAS, D., et al., (2000). Protein phosphatase $1 \beta$ is required for the maintenance of muscle attachments. Curr Biol. 10: 269-272.

RAI, M., KATTI, P. and NONGTHOMBA, U. (2014). Drosophila Erect wing (Ewg) controls mitochondrial fusion during muscle growth and maintenance by regulation of the Opa1-like gene. J. Cell Sci. 127: 191-203.

REEDY, M. C. and BEALL, C. (1993). Ultrastructure of developing flight muscle in Drosophila. I. Assembly of myofibrils. Dev. Biol. 160: 443-465.

REEDY, M. C., BULLARD, B. and VIGOREAUX, J. O. (2000). Flightin Is Essential for Thick Filament Assembly and Sarcomere Stability in Drosophila Flight Muscles. J Cell Biol. 151: 1483-1499.

RIVLIN, P. K., SCHNEIDERMAN, A. M. and BOOKER, R. (2000). Imaginal Pioneers Prefigure the Formation of Adult Thoracic Muscles in Drosophila melanogaster. Dev. Biol. 222: 450-459.

SALVI, S. S., KUMAR, R. P., RAMACHANDRA, N. B., SPARROW, J. C. and NONGTHOMBA, U. (2012). Mutations in Drosophila myosin rod cause defects in myofibril assembly. J. Mol Biol. 419: 22-40.

SANDSTROM, D. J. and RESTIFO, L. L. (1999). Epidermal tendon cells require Broad Complex function for correct attachment of the indirect flight muscles in Drosophila melanogaster. J. Cell Sci. 112: 4051-4065.

SANDSTROM, D. J., BAYER, C. A., FRISTROM, J. W. and RESTIFO, L. L. (1997). Broad-Complex Transcription Factors Regulate Thoracic Muscle Attachment in Drosophila. Dev Biol. 181: 168-185.

SELDIN, M. M., PETERSON, J. M., BYERLY, M. S., WEI, Z. and WONG, G. W. (2012). Myonectin (CTRP15), a novel myokine that links skeletal muscle to systemic lipid homeostasis. J. Biol. Chem. 287: 11968-11980.

SEVDALI, M., KUMAR, V., PECKHAM, M. and SPARROW, J. (2013). Human congenital myopathy actin mutants cause myopathy and alter Z-disc structure in Drosophila flight muscle. Neuromuscul Disord. 23: 243-255.

SHCHERBATA, H. R., YATSENKO, A. S., PATTERSON, L., SOOD, V. D. et al., (2007) Dissecting muscle and neuronal disorders in a Drosophila model of muscular dystrophy. EMBO J. 26: 481-93

SHWARTZ, A., DHANYASI, N., SCHEJTER, E. D. and SHILO, B. (2016). The Drosophila formin Fhos is a primary mediator of sarcomeric thin-filament array assembly. Elife 5: e16540.

SPLETTER, M. L., BARZ, C., YEROSLAVIZ, A., ZHANG, X., LEMKE, S. B., et al., (2018). A transcriptomics resource reveals a transcriptional transition during ordered sarcomere morphogenesis in flight muscle. Elife 7: e34058.

STERRENBURG, E., TURK, R., 'T HOEN, P. A., VAN DEUTEKOM, J. C., BOER, J. M, VAN OMMEN, G. J. and DEN DUNNEN, J.T. (2004). Large-scale gene expression analysis of human skeletal myoblast differentiation. Neuromuscu Disord. 14: 507-518.

SUGGS, J. A., MELKANI, G. C., GLASHEEN, B. M., DETOR, M. M. et al., (2017). A Drosophila model of dominant inclusion body myopathy type 3 shows diminished myosin kinetics that reduce muscle power and yield myofibrillar defects. Dis Model Mech. 10: 761-771.

SWANK, D. M., KRONERT, W. A., BERNSTEIN, S. I. and MAUGHAN D. W. (2004) Alternative $\mathrm{N}$-terminal regions of Drosophila myosin heavy chain tune muscle kinetics for optimal power output. Biophys. J. 87: 1805-1814.

TAYLOR, M.V. (2006). Muscle Development in Drosophila. In: Sink, H. (Ed.), Comparison of muscle development in Drosophila and vertebrates. Landes Bioscience, USA

TOMCZAK, K. K., MARINESCU, V. D., RAMONI, M. F., SANOUDOU, D. et al., (2003). Expression profiling and identification of novel genes involved in myogenic differentiation. FASEB 18: 403-405.

UEYAMA, M., AKIMOTO, Y., ICHIMIYA, T., UEDA, R. et al., (2010). Increased 
apoptosis of myoblasts in Drosophila model for the Walker-Warburg syndrome. PLoS One 5: e11557

VEGA-MACAYA, F., MANIEU, C., VALDIVIA, M. and MLODZIK, M. (2016). Establishment of the Muscle-Tendon Junction During Thorax Morphogenesis in Drosophila Requires. Genetics 204: 1139-1149.

VIGOREAUX, J. O. (2001). Genetics of Drosophila flight muscle myofibril: a window into the biology of complex system. BioEssays 23: 1047-1063.

VIGOREAUX, J. O. (2006). Molecular basis of muscle structure, pp. 143-156 in Muscle Development in Drosophila, edited by Helen Sink. Springer/Landes Bioscience, New York.

VISWANATHAN, M. C., SCHMIDT, W., RYNKIEWICZ, M. J., AGARWAL, K., GAO, J., KATZ, J., LEHMAN, W. and CAMMARATO, A. (2017). Distortion of the Actin A-Triad Results in Contractile Disinhibition and Cardiomyopathy. Cell Rep. 20:
2612-2625.

WANG, Y., MELKANI, G. C., SUGGS, J. A., MELKANI, A., KRONERT, W. A., CAMMARATO, A. and BERNSTEIN, S. I. (2012). Expression of the inclusion body myopathy 3 mutation in Drosophila depresses myosin function and stability and recapitulates muscle inclusions and weakness. Mol Biol Cell. 23: 2057-2065.

WEITKUNAT, M., KAYA-ÇOPUR, A., GRILL, S. W. and SCHNORRER, F. (2014). Tension and force-resistant attachment are essential for myofibrillogenesis in Drosophila flight muscle. Curr. Biol. 24: 705-716.

ZENG, L., AKASAKI, Y., SATO, K., OUCHI, N., IZUMIYA, Y. and WALSH, K. (2010). Insulin-like 6 is induced by muscle injury and functions as a regenerative factor. J. Biol. Chem. 285: 36060-36069.

ZHAO, X. and KARPAC, J. (2017). Muscle Directs Diurnal Energy Homeostasis through a Myokine-Dependent Hormone Module in Drosophila. Curr. Biol. 27: 1941-1955. 


\section{Further Related Reading, published previously in the Int. J. Dev. Biol.}

Reservoirs for repair? Damage-responsive stem cells and adult tissue regeneration in Drosophila Silvia Schwartz and Christa Rhiner Int. J. Dev. Biol. (2018) 62: 465-471 https://doi.org/10.1387/ijdb.180056cr

Adhesion molecule Kirrel3/Neph2 is required for the elongated shape of myocytes during skeletal muscle differentiation Yael Tamir-Livne, Raeda Mubariki and Eyal Bengal

Int. J. Dev. Biol. (2017) 61: 337-345

https://doi.org/10.1387/ijdb.170005eb

Building functional units of movement-generation and movement-sensation in the embryo

Peleg Hasson, Talila Volk and Adi Salzberg

Int. J. Dev. Biol. (2017) 61: 171-178

https://doi.org/10.1387/ijdb.160279as

mRNA cycles through hypoxia-induced stress granules in live Drosophila embryonic muscles

Annelies M.A. van der Laan, Alice M.C. van Gemert, Roeland W. Dirks, Jasprina N. Noordermeer, Lee G. Fradkin, Hans J. Tanke and Carolina R. Jost

Int. J. Dev. Biol. (2012) 56: 701-709

https://doi.org/10.1387/ijdb.103172al

Plasticity within the lateral somatic mesoderm of Drosophila embryos

T Jagla, F Bellard, J L Vonesch, M Bellard, B Dastugue and K Jagla

Int. J. Dev. Biol. (1999) 43: 571-573

http://www.intjdevbiol.com/web/paper/10610031

Expression of myosin heavy chain isoforms during development of domestic pigeon pectoralis muscle B W Rosser, M Wick, D M Waldbillig, D J Wright, C M Farrar and E Bandman Int. J. Dev. Biol. (1998) 42: 653-661

http://www.intjdevbiol.com/web/paper/9712520

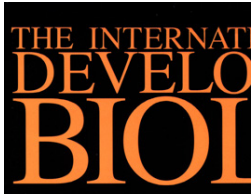

Volume 42 No. 3

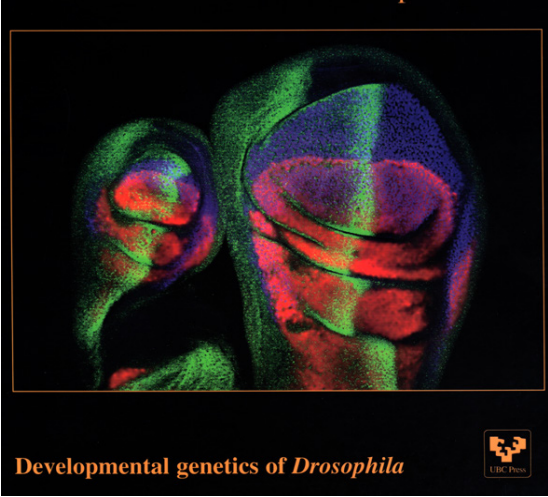

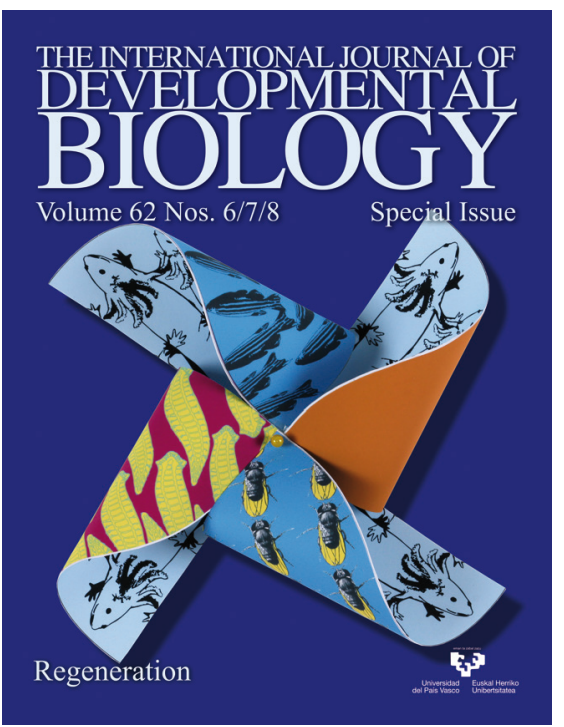

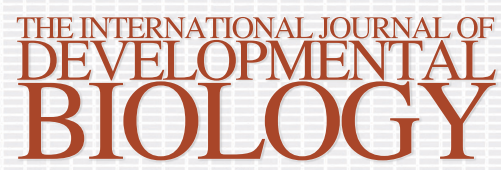

Volume 62 Nos. $11 / 12$

Special Issue

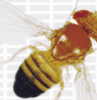

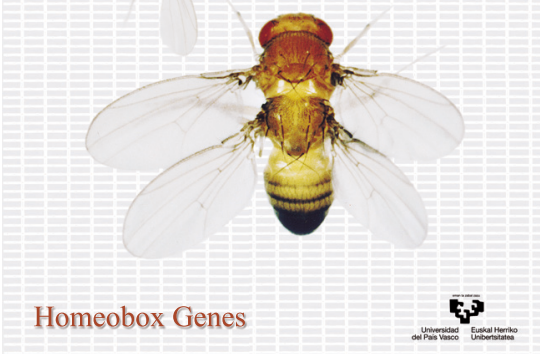

